\title{
Las metáforas del mar en Mar caníbal de Uriel Quesada
}

\author{
Diana Martínez Alpízar \\ Universidad de Costa Rica, Costa Rica \\ dimartinezalpizar@gmail.com \\ https://orcid.org/0000-0001-8751-6891
}

Recibido: 22 de febrero 2018

Aceptado: 20 de mayo 2018

\section{Resumen:}

A partir de la teorización de la metáfora hecha por Paul Ricoeur, el artículo ofrece una lectura de la novela Mar caníbal (2016) del costarricense Uriel Quesada. En este texto, el mar, más allá de un simple punto geográfico, adquiere diferentes significados, según el desarrollo de cada uno de los personajes. Se concluye que, en el texto en análisis, el mar, como elemento polisemántico, se configura como una metáfora del peligro y de la culpa, a la vez que del deseo y de la otredad.

Palabras clave: metáfora; Uriel Quesada; literatura costarricense; novela costarricense; Paul Ricouer.

\section{The Metaphors of the Sea in Mar Caníbal by Uriel Quesada}

\begin{abstract}
:
Based on theorization of metaphor made by Paul Ricoeur, this article offers an interpretation of Mar Caníbal (2016), novel written by the Costarrican Uriel Quesada. In this text, the sea is more than a geographic point, it acquires several meanings, according to the developed of the characters. In conclusion, in the text analyzed, the sea, as a polysemantic element, shapes as a metaphor of the danger and the guiltiness, but also it works like a metaphor of the desire and the otherness.
\end{abstract}

Keywords: metaphor, Uriel Quesada; Costarrican literature; Costarrican novel; Paul Ricoeur.

\section{(C) $(\Theta \odot$}

La Revista Estudios es editada por la Universidad de Costa Rica y se distribuye bajo una Licencia Creative Commons Atribución-NoComercial-CompartirIgual 3.0 Costa Rica. Para más información envíe un mensaje a 
Especial: Naturaleza amena y naturaleza agreste en las letras hispánicas

Cotidiana y omnipresente, conceptualizada desde la retórica como un tropo literario que adorna el lenguaje, la metáfora en realidad es una estrategia clave en el funcionamiento del lenguaje y de, claro está, la literatura. Específicamente, este artículo se interesa en analizar una de ellas. Esta sería el mar como metáfora en la novela Mar caníbal (2016), escrita por el costarricense Uriel Quesada. Desde la lectura ofrecida en este artículo, este elemento natural se configura no solo como uno de los espacios donde se desarrollan pasajes específicos del texto, sino que, además, es posible interpretarlo como una metáfora asociada al desarrollo de cada uno de los personajes', en especial de Gonzalo/Chalito, el protagonista de la historia.

Antes del análisis de la novela, se debe establecer algunas premisas teóricas útiles para la lectura propuesta. Para ello, se parte de los postulados del filósofo francés Paul Ricouer. Este argumenta que la metáfora no es una simple sustitución de un término por otro, sino más "una innovación semántica" (Ricoeur, 1998, p.118,), basada en "el poder creativo del lenguaje" (Ricoeur, 1998, p. 118). Es decir, el mecanismo de la metáfora "desdobla" ("tuerce", diría el filósofo francés), mediante el establecimiento de analogías, el lenguaje al ofrecer dos interpretaciones: la primera literal que nos permite acceder a una segunda, la cual a su vez completa la anterior. En pocas palabras, las metáforas revitalizan el lenguaje, al poner a funcionar su capacidad polisemántica.

Para que esta magia metafórica suceda, indica Ricoeur (1998), es necesario trazar analogías que transgredan, que violenten "las reglas semánticas que determinan lo apropiado en la aplicación de predicados" (p. 128). La genialidad de la metáfora reside entonces en ver la semejanza en dos elementos desiguales, en "hacer sentido de un sinsentido" (p. 128): "En otras palabras, el poder de la metáfora consiste en romper, en cruzar las categorizaciones previas y establecer nuevas frontera lógicas sobre las ruinas de las anteriores". (Ricoeur, 1998, p. 131).

\section{(C) $(00$}

La Revista Estudios es editada por la Universidad de Costa Rica y se distribuye bajo una Licencia Creative Commons Atribución-NoComercial-CompartirIgual 3.0 Costa Rica. Para más información envíe un mensaje a 
Especial: Naturaleza amena y naturaleza agreste en las letras hispánicas

En consecuencia, la metáfora nos permite reescribir la realidad y ver diferentes formas de ver el mundo, una visión otra, ajena a la dominante: "(...) La estrategia del discurso implicado en el lenguaje metafórico no es mejorar la comunicación ni asegurar la univocidad en la argumentación sino quebrar y aumentar nuestro sentido de la realidad al quebrantar y aumentar nuestro lenguaje" (Ricoeur, 1998, p.134).

¿Y dónde reside entonces este poder de la metáfora? ¿Y cuál es su relación con la literatura? Con respecto a la primera interrogante, Ricoeur (1980) aclara que la metáfora no se encuentra en la palabra aislada, "no hay metáforas en el diccionario" (p. 136), sino en las interrelaciones establecidas entre ellas en un contexto específico y en un momento determinado: "Las palabras no tienen significación propia porque no tienen significación en propiedad; y no poseen ningún sentido en sí mismas, porque es el discurso, tomado como un todo, el que hace sentido de un modo indiviso" (Ricoeur, 1980, p.112).

Si se sigue la idea anteriormente propuesta, la metáfora depende del discurso. Y es justamente esta afirmación la que nos permite ligarla con la literatura: cada obra literaria, como entidad lingüística, como un todo organizado, opera como un discurso:

Precisamente, la literatura nos presenta un discurso en el que hay un abanico de significaciones posibles, sin que el lector se vea obligado a elegir entre ellas. De este modo puede obtenerse una definición semántica de la literatura, es decir, una definición en términos de significación, partiendo de la proporción de significaciones secundarias implícitas o sugeridas que comporta un discurso (Ricoeur, 1980, p.129).

En una primera instancia, en un nivel primario de significación, la obra refiere a, según Ricoeur (1980), "«al mundo de la obra»: ¿qué cuenta?, ¿qué personalidad refleja?, ¿qué sentimientos expresa?, ¿cuál es su finalidad?" (p. 130). En el segundo nivel, en cambio, estarían los sentidos múltiples subyacentes en el primero. Vale la pena aclarar que Ricoeur prefiere hablar de "sentidos 
Especial: Naturaleza amena y naturaleza agreste en las letras hispánicas múltiples" y no de "ambigüedad", "pues en realidad sólo hay ambigüedad cuando, de las dos significaciones posibles, sólo se necesita una, y el contexto no da pie para decidir entre ellas" (Ricoeur, 1980, p. 129).

La obra literaria es entonces un discurso polisémico, un juego de interpretaciones en el cual el lector selecciona núcleos interpretativos, a partir de los cuales elaborará "el trabajo del sentido" (Ricouer, 1980, p. 135), es decir, las infinitas connotaciones surgidas a partir de su lectura. Para ser parte de este juego no se necesita ser un genio, como proponía Aristóteles, sino solo actuar de manera congruente. Es decir, no se debe forzar al texto a decir algo que no dice:

Si comparamos la lectura con la ejecución de una partitura musical, podemos decir que la lógica de la explicación enseña la ejecución correcta del poema, por más que toda ejecución sea singular e individual. Si no perdemos de vista que el principio de plenitud completa al de congruencia, y que la complejidad corrige la coherencia, deberemos admitir que el principio de economía que preside esta lógica no se limita a excluir imposibilidades; invita también a «maximalizar» el sentido, a sacar del poema la mayor significación posible; una cosa debe tener siempre presente esta lógica: la distinción entre sacar el sentido del poema y atribuírselo a la fuerza (Ricoeur, 1980, p135).

Una vez analizada y comentada sucintamente la teoría con respecto a la metáfora, y con la esperanza de ser congruentes con el texto en análisis, amén de no forzar el texto, como advierte Ricoeur, interesa ahora iniciar el análisis del texto en cuestión. En un primer lugar, es indispensable hacer referencia aspectos generales de Mar caníbal (2016).

La novela narra la historia de Gonzalo, quien recuerda el viaje hecho en los inicios de su adolescencia, junto a su madre, Ada, a Hawskbill, un alejado pueblo costero en la provincia de Limón, en el atlántico costarricense. Ambos viajan para ayudar a Berta y Antonia, sus primas. Estas desean llevarse de regreso a Cartago,

\section{(C) $(\otimes \odot \odot$}

La Revista Estudios es editada por la Universidad de Costa Rica y se distribuye bajo una Licencia Creative Commons Atribución-NoComercial-CompartirIgual 3.0 Costa Rica. Para más información envíe un mensaje a 
Especial: Naturaleza amena y naturaleza agreste en las letras hispánicas ciudad de origen, a su padre, Gregorio Malverde; a Gema, su madrastra, y a Ventura, su hermana adoptiva. La pareja ha envejecido, la casa donde habita se ha deteriorado y las hijas, preocupadas por el cada vez más escaso patrimonio familiar, a la vez que recelosas de su hermana adoptiva, desean vender el otrora hermoso caserón.

Este viaje hacia el Caribe se realiza tanto a nivel geográfico, dado que los personajes se trasladan del conservador Cartago al inhóspito Hawsbill, como a nivel temporal, a través del recurso de la memoria, pues en la mayor parte de los capítulos, a través de un narrador en primera persona, se leen los recuerdos de un Gonzalo ya adulto. Otra de las voces narradoras la constituye Natalio Rojas, íntimo amigo de Gregorio Malverde y, por lo tanto, testigo de todos sus secretos. Ambos personajes, como indica Rojas González (2016), son homosexuales, por ende, sujetos marginados en un mundo patriarcal.

En cuanto a la presencia del mar, este aparece incluso desde el primer párrafo de la novela. La cita es larga, pero valiosa:

Yo soy ese chiquillo que está sentado en la playa. Le da la espalda a un puñado de palmeras que sombrean y protegen las casas de los vientos. Delante de mí un mar turquesa parece dispuesto a destrozar las piedras que toca. No se rinde a los pies del muchachito, pues hasta la última espuma se recoge velozmente sobre sí misma, tan inquieta y poco dispuesta a que los humanos la acaricien. El chiquillo desea estar solo, pero sospecha que Ada o las primas lo están vigilando ocultas en la vegetación (Quesada Román, 2016, p.13. El destacado es nuestro).

Como se observa, el mar se vincula a la destrucción, a la obcecación, a la inquietud y a la soledad, pero adquiere un valor específico según cada personaje. En particular, para Gonzalo/Chalito, el protagonista del texto, el mar es una figura ambivalente, relacionada, por un lado, con el miedo, el pecado, la culpa, las prohibiciones, el temor a la transgresión y su consecuente castigo. Estas

\section{(c) (i) (2)}

La Revista Estudios es editada por la Universidad de Costa Rica y se distribuye bajo una Licencia Creative Commons Atribución-NoComercial-CompartirIgual 3.0 Costa Rica. Para más información envíe un mensaje a 
Especial: Naturaleza amena y naturaleza agreste en las letras hispánicas asociaciones con el mar se evidencian claramente en la prohibición materna de entrar al mar, a pesar de la fascinación de Chalito. Esta es la primera vez que el adolescente lo observa de cerca:

(...) Mira el movimiento de las olas con fascinación y espanto: sus pequeñas proezas han surgido, paradójicamente, de la colisión de ambas fuerzas. Pero esta vez Ada, su madre, ha sido clara por cuanto no desea ni siquiera toque el agua, pues todo en Hawsbill es salvaje, peligroso, sucio (Quesada Román, 2016, p.13).

De esta forma, entrar en contacto con el agua se convierte en una transgresión a la autoridad, encarnada en la voz materna, e implica contaminarse. A pesar de estos peligros, Chalito no podrá resistirse al mar, es decir, al deseo. Este sería, entonces, la otra metáfora del mar para el personaje. Dicho deseo se relaciona, en una primera instancia, con la pérdida de la virginidad de Gonzalo en las aguas del mar de Hawsbill.

El compañero de Chalito en este primer encuentro es Tobías, un adolescente del pueblo que se prostituye con los extranjeros que llegan a buscar aventuras pasajeras y exóticas a Hawsbill. Él ofrece su cuerpo a los visitantes y con Chalo no es la excepción. Eso sí, la transacción monetaria no se acuerda abiertamente: Tobías le ofrece a Chalito llevarlo a ver las tortugas y los manatíes, a cambio de cierta cantidad de dinero. Para conseguirlo, Gonzalo le roba la plata a su madre.

Este pasaje iniciático en la vida de Chalo resulta fundamental para comprender el funcionamiento del mar como metáfora del deseo en la novela. Las analogías entre ambos son recurrentes. La marea sube conforme la excitación sexual de la pareja, el vaivén del mar se compara con el del deseo y ambos personajes, durante el encuentro sexual, se comparan con monstruos y seres marinos:

\section{(C) $(00$}

La Revista Estudios es editada por la Universidad de Costa Rica y se distribuye bajo una Licencia Creative Commons Atribución-NoComercial-CompartirIgual 3.0 Costa Rica. Para más información envíe un mensaje a 
(...) Tobías había puesto a Gonzalo bajo el peso de su cuerpo, y le había mordido suavemente el lóbulo de la oreja y el cuello y luego había descendido por el cuerpo del chiquillo hasta su sexo. "Esto es lo que quiero que me hagás", le dijo antes de dejarse caer en la arena y extender su cuerpo como seguramente - había pensado Gonzalo- lo harían los animales en las inmensidades del océano. Él se imaginó a sí mismo como un pequeño pez adherido al cuerpo de uno mayor, del cual se alimentaba y al cual no limpiaba sino que le daba placer. Así los dos se volvían parte de la misma experiencia, del ir y venir por las profundidades a las que no muchos accedían. (Quesada Roman, 2016, p. 176).

Ahora bien, para el personaje de Gonzalo, el mar representa el deseo no solo en un plano sexual-homoerótico, sino que, de igual forma, metaforiza las ansias por conocerse, por mostrarse sin miedos y sin culpas ante los demás: "liberarse de un peso" (Quesada Román, 2016, p. 146). En este sentido, al sumergirse en el mar con Tobías ocurre una especie de muerte y renacimiento de Chalito, quien se convierte en Gonzalo. El mar, como bien explica Cirlot (1992), indica entonces tanto el cierre como el inicio de un ciclo: el paso de la inocencia a la adultez. Después de este encuentro sexual, el personaje es y no el mismo de antes:

(...) Para Tobías, lo que había pasado probablemente era otra experiencia más, como si la realidad de ese instante fuera similar a la de unas horas antes, cuando esperaba sentado en la playa de Hawksbill, similar pero no la misma, no podría serlo. Y él quería hablar de ello, decirle a Tobías que ambos eran los mismos y otros a la vez, y como consecuencia el mar, la vegetación, la arena, las rocas, todo era otro (Quesada Román, 2016. p.178).

Surgen, en estos momentos, dos preguntas a responder en el resto del artículo: ¿metaforiza el mar las mismas analogías del deseo para el resto de personajes?, ¿cuál es la relación de estas metáforas con el título de la novela?

\section{(C) $(00$}

La Revista Estudios es editada por la Universidad de Costa Rica y se distribuye bajo una Licencia Creative Commons Atribución-NoComercial-CompartirIgual 3.0 Costa Rica. Para más información envíe un mensaje a 
Especial: Naturaleza amena y naturaleza agreste en las letras hispánicas

En relación con la primera pregunta, desde la lectura acá propuesta, el mar sí se metaforiza como el deseo para Ventura, aunque en su caso su resolución es diferente. Comprada desde bebé por Gregorio Malverde, menospreciada por su familia por su piel negra y rechazada por los negros de la comunidad al ser criada por blancos, por más que intente calzar Ventura, en oposición a su nombre, ha tenido una vida triste y solitaria. Por eso mismo, si bien para ella el mar también representa el deseo, ella lo rechaza. Esta evasión la observamos en varios pasajes de la novela: cuando Tobías se le acerca y la acaricia, pero ella termina finalmente rehuyéndolo y rechazándolo; o bien cuando la joven contempla el mar, pero decide no mojar sus pies. Eso sí, el personaje se ve, al igual que Chalito, tentado por el mar. Este se manifiesta en los ojos de Gema, su madre adoptiva, quien nunca la ha querido. La joven queda atrapada por la "profundidad marina" de estos ojos:

Ventura, sin entenderlo muy bien, sintió que reconocía esos ojos, y no pudo evitar acordarse de ciertos rincones de la playa que le parecían solo suyos, donde era placentero meterse al mar y ver el fondo apenas agitado por el reflejo del sol sobre la superficie del agua. Era fascinante ver avanzar poco a poco, sentir como el mar jugaba a devorarla abriéndole paso con gentileza, volviéndose calmo e inofensivo unos segundos mientras ella se acurrucaba para mirar las formaciones de coral y sentir la arena fugarse al contacto de sus pies (...) (Quesada Román, 2016, p. 107).

Ventura, al observar los ojos de Gema, capta en ellos su propio deseo y, al hacerlo, erotiza el cuerpo de su madre adoptiva, en un juego de miradas en el que ambas quedan atrapadas. El otro, un espejo terrorífico:

\section{(C) $(00$}

La Revista Estudios es editada por la Universidad de Costa Rica y se distribuye bajo una Licencia Creative Commons Atribución-NoComercial-CompartirIgual 3.0 Costa Rica. Para más información envíe un mensaje a 
-No me vea así- suplicó casi en un susurro, pero la misma Gema no era capaz de apartar la vista a la muchacha.

Le sostenía la mirada a Ventura como invitándola a ver más, ojalá esos ojos pudieran tocarle la barbilla y buscaran sus labios, nunca tan rojos como hubiera querido, por lo que se los mordió para animar el color o quizás para atrapar esa mirada y saborearla, comprender por completo su forma y textura, jugar un rato con ella, pero ya la sensación se había alejado hacia su cuello, no tan firme como antes, pero aún hermoso" (Quesada Román, 2016, p. 109).

No obstante esta tentación por caer en el mar, Ventura no sucumbe y al final de la novela huye de Hawsbill, sola, sin dinero y culpabilizada injustamente por el robo del dinero a Ada. Dinero que, como sabemos, en realidad fue tomado por Gonzalo. Para la hija adoptiva de los Malverde, no hay posibilidad de descubrimientos íntimos ni de transcender a través del placer; quizá, porque a diferencia de Chalito, ella nunca logra aceptarse a sí misma.

Pasemos, en seguida, a analizar otro personaje más. Nativo de Hawskbill, Tobías, en contraste con los turistas que llegan repletos de deseos de conocer el exótico lugar, anhela más bien lo opuesto: que alguno de sus clientes lo saque del pueblo, que lo lleve a conocer otros lugares. Sin embargo, sus expectativas nunca se concretan: "No recordaba haber llorado por nadie, sino a causa de muchos, de sus promesas de sacarlo de Hawsbill y hacerse cargo de él. Habían sido llantos de rabia, de esos que uno sufre cuando las cosas no salen como se ha esperado" (Quesada Román, 2016, p. 145)

Así pues para Tobías, el mar se relaciona con la monotonía y con los deseos de fuga de un lugar que no le ofrece nada, más allá de un futuro en la prostitución. El personaje, a pesar de lo anterior, guarda una estrecha relación con el mar, pero en un sentido distinto: Tobías es descrito como una criatura marina, específicamente como una sirena que embauca, no a los marineros, pero sí a los turistas con promesas falsas. Uno de ellos es Chalito, quien durante su encuentro

\section{(C) $\odot \Theta \odot$}

La Revista Estudios es editada por la Universidad de Costa Rica y se distribuye bajo una Licencia Creative Commons Atribución-NoComercial-CompartirIgual 3.0 Costa Rica. Para más información envíe un mensaje a 
Especial: Naturaleza amena y naturaleza agreste en las letras hispánicas

sexual con Tobías escucha gemir a Tobías, "pero en su fantasía ese sonido era un canto y un llamado" (Quesada Román, 2016, p. 177).

En cuanto al resto de la familia Malverde, el mar se relaciona con el pecado y las prohibiciones (Aida), o bien con una otredad exótica (en el caso de Gema, Berta, Toña, Gregorio). Para todos estos personajes, desde su perspectiva católica, conservadora y cartaginesa, Hawksbill y su mar circundante se asimilan con la barbarie, con el atraso material y cultural, con una población mayormente negra o indígena.

Esta lectura se refuerza en varios pasajes de la novela. Nos detendremos a analizar algunos de ellos. El primero, la comparación hecha por Gema en la cual se asimila al pueblo y al mar de Hawsbill como el lugar de lo abyecto. Para ella, Hawksbill es "una botella como estos monstruos que guardan los doctores en su consultorio" (Quesada Román, 2016, p. 121). En esta misma línea de análisis, podríamos incluir las constantes quejas de Gregorio Malverde sobre la haraganería de los habitantes de Hawksbill, estos "pescadores vagabundos" (p. 182) y su descripción del ambiente físico como inhóspito e infecundo: "selva de mierda”, "con el mar sucio, mar cloaca, manoteando en las piedras innumerables de la playa, formando remolinos como para acechar a las personas, llevárselas hasta su estómago y destruirlas" (Quesada Román, 2016, p. 125 El destacado es nuestro). Nótese en particular la adjetivación y personificación del mar, en la cual se le degrada y se le otorga una agentividad nociva.

En esta misma línea de interpretación (el mar como metáfora de una otredad peligrosa), otro elemento significativo lo encontramos en la ausencia de iglesia alguna en el pueblo, carencia que reforzaría la idea de que Hawksbill es un sitio olvidado incluso por Dios, tal y como lo expresan los miembros de la familia San Román. Por ejemplo, para Gema, al igual que para Esperanza San Román, el pueblo y su mar se convierten en una especie de infierno, un lugar donde deben

\section{(c) (i) (2)}

La Revista Estudios es editada por la Universidad de Costa Rica y se distribuye bajo una Licencia Creative Commons Atribución-NoComercial-CompartirIgual 3.0 Costa Rica. Para más información envíe un mensaje a 
Especial: Naturaleza amena y naturaleza agreste en las letras hispánicas expiar sus pecados. Lo anterior se evidencia claramente en la siguiente confesión de Esperanza San Román:

(...) Aunque los habitantes del pueblo digan que él está en todas partes, yo no lo puedo creer. Dios necesita su iglesia bonita, necesita estar rodeado de santos y un cura frente al rebaño. Aquí no hay nada, solamente la selva llena de animales y ruidos, un mar que no me deja dormir y gente que no es como nosotros. Pero yo ya sabía que todo eso era parte de mi castigo y lo he aceptado con humildad (Quesada Román, 2016, p. 196).

Esta imposibilidad de adaptarse a Hawsbill y a sus entornos marítimos se destaca también en la exclusión de la casona donde habitan los Malverde, única casa del pueblo desconectada del acueducto. La casa resulta, entonces, un símbolo de la incapacidad de los miembros de esta familia para incorporarse al Hawsbill.

En este sentido, esta metáfora del mar como una otredad peligrosa e incomprensible permite establecer una relación entre el texto de Quesada y la conformación histórica de la identidad costarricense. Para nadie es un secreto que, como indican Hidalgo (2004) y Jiménez Matarrita (2013), la identidad costarricense (entendida en el sentido de comunidad política imaginada) desde sus inicios, a finales del siglo XIX, se basó en una serie de características que no coincidían con la realidad: una supuesta homogeneidad étnica, anclada en el Valle Central y basada en la sangre europea que fluía por la venas de un campesino trabajador y pacífico. Esta construcción, bien apunta Hidalgo (2004), implicó:

(...) una experiencia profunda de exclusión de la diversidad cultural, social y de género. Esta experiencia de exclusión va a convertirse, por lo tanto, en una condición primordial en el imaginario social sobre la nación costarricense que surge desde los mismos orígenes del Estado nacional (Hidalgo, 2004, p. 21).

\section{(c) (i) (-)}

La Revista Estudios es editada por la Universidad de Costa Rica y se distribuye bajo una Licencia Creative Commons Atribución-NoComercial-CompartirIgual 3.0 Costa Rica. Para más información envíe un mensaje a 
Especial: Naturaleza amena y naturaleza agreste en las letras hispánicas

Justamente esta exclusión tan presente en los orígenes del imaginario nacional se repite también en el actuar y en el decir de los Malverde. Sus integrantes elaboran su propio imaginario exótico de los otros como incomprensibles y distantes, lo cual a su vez implica graves repercusiones, ya que “(...) es un conocimiento que construye al otro como objeto, por tanto es siempre un conocimiento superficial y simplificado. Un problema en esta política de la simplificación conduce a la creación del estereotipo del sujeto exótico" (Weiz, 2007, p. 15).

Con base en lo anterior, se coincide plenamente con la lectura de Rojas González (2016), quien argumenta que Mar caníbal "cuestiona la identidad costarricense haciéndonos ver que lo que no queremos ver de nosotros mismos, es decir, que somos una sociedad sexista, racista y discriminatoria" (Rojas González, 2016, p. 222).

No podríamos cerrar este análisis sin abordar un último punto: la adjetivación del mar como "caníbal", presente incluso desde el título de la novela. Esta característica se relaciona, desde la lectura propuesta, con el tema de la otredad/alteridad que, como se ha venido explicando anteriormente, constituye uno de los principales del texto.

Para este fin, es necesario ahondar brevemente en el origen etimológico e histórico de la palabra "caníbal". Transcrita por Cristóbal Colón en su diario del 11 de diciembre de 1492, la palabra caniba aludía, según Pancorbo (2008), a la voz tribal "cariba". Sin embargo, como bien explica Tzvetan Todorov (1982), Colón entiende caniba como gente del Gran Khan, "Pero también comprende que según los indios estos personajes tienen cabezas de perro (del español can...) con las cuales, precisamente, les comen" (Todorov, 1982, p.131). De esta manera, los caribes, etnia indígena que habitaba en las Antillas, pasan a la historia como antropófagos belicosos, pecadores malvados, "en contraposición a los taínos pacíficos" (Pancorbo, 2010, p.104). Esta visión exótica y simplificadora hacia la 
Especial: Naturaleza amena y naturaleza agreste en las letras hispánicas

otredad la vemos no solo en los diarios de Colón, con esta oposición entre caníbales y taínos, sino que también se reproduce en la visión de mundo de los Malverde, como se explicó párrafos atrás.

La novela de Quesada juega entonces con las múltiples metáforas de este mar caribe, caníbal. El mismo elemento puede ser letal o tentador, según la perspectiva de cada personaje. Sin embargo, y desde la lectura acá propuesta, en la novela de Quesada, el peligro no es ser devorado por el mar (el deseo por el otro), sino resistirse a este. Dejar que el otro me devore, perder parte del ser propio en ese encuentro, tal como le ocurre a Gonzalo en la escena de la felación con Tobías, permite el autodescubrimiento, así como la transformación y la liberación de miedos ante prohibiciones y tabúes sociales. No en vano el viejo Natalio le ruega Chalito que se libere del secreto. "Andá a Hawsbill y echalo al mar. Volvé liviano, listo para seguir creciendo y ser feliz" (Román Quesada, 2016. p.205).

En contraposición, cerrarse al otro, a la atracción que este me produce, como sucede con el resto de los Malverde, implica vivir en una eterna fuga (Ventura), en la paranoia (Gema), o bien acabar en la muerte (Gregorio). El otro, nos dice el texto en análisis, es siempre un mar de posibilidades.

\section{(c) (i) (2)}

La Revista Estudios es editada por la Universidad de Costa Rica y se distribuye bajo una Licencia Creative Commons Atribución-NoComercial-CompartirIgual 3.0 Costa Rica. Para más información envíe un mensaje a 
Especial: Naturaleza amena y naturaleza agreste en las letras hispánicas

\section{REFERENCIAS BIBLIOGRÁFICAS}

Cirlot, J. (1992). Diccionario de símbolos. Barcelona: Editorial Labor.

Hidalgo, R. (2004). Historia de las mujeres en el espacio público de Costa Rica ante el cambio del siglo XIX al XX. Cuaderno de Ciencias Sociales, 132, 1764. Recuperado de http://www.flacso.or.cr/

Jiménez Matarrita, A. (2013). El imposible país de los filósofos: el discurso filósofo y la intervención de Costa Rica. San José: Editorial UCR.

Pancorbo, L. (2010). Abecedario de antropologías. Madrid: Siglo XXI de España Editores. Recuperado de http://www.ebrary.com

Pancorbo, L. (2008). El banquete humano: una historia cultural del canibalismo. Madrid: Siglo XXI de España Editores. Recuperado de http://www.ebrary.com

Quesada Román, U. (2016). Mar caníbal. San José: Uruk Editores.

Ricoeur, P. (1998). Creatividad en el lenguaje. Signo y Pensamiento (12) 117-135. Recuperado de http://revistas.javeriana.edu.co

Ricoeur, P. (1980). La metáfora viva. Madrid: Ediciones Europa.

Rojas González, P. (2016). Uriel Quesada, Mar Caníbal. Cuadernos Intercambio sobre Centroamérica y el Caribe, 13 (2) 221-224. Recuperado de https://revistas.ucr.ac.cr/index

Todorov, T. (1982). La conquista de América, el problema del otro. México: Siglo Veintiuno Editores.

Weisz, G. (2007). Tinta del exotismo: literatura de la otredad. México, D.F: Fondo de Cultura Económica. Recuperado de http://www.ebrary.com

\section{NOTAS}

\footnotetext{
¡1. No se incluye en el análisis al personaje Natalio Rojas, pues la constitución de su identidad gira no entorno a su relación con Hawsbill y su mar, sino con Cartago. A través de este personaje, el texto representa a esta ciudad como un pueblo conservador en el cual el chisme y la religión funcionan como mecanismos de control social.
}

\section{(C) $(\triangle 0$}

La Revista Estudios es editada por la Universidad de Costa Rica y se distribuye bajo una Licencia Creative Commons Atribución-NoComercial-CompartirIgual 3.0 Costa Rica. Para más información envíe un mensaje a 